\title{
Application of Profit Quality Pyramid Model in iFLYTEK
}

\author{
Jing Zhou \\ School of Economics \& Management, Nanjing University of Science and Technology, Nanjing \\ 210094, China \\ 1037231087@qq.com
}

Keywords: Profit quality, added value, balanced development, iFLYTEK.

\begin{abstract}
In the trend of artificial intelligence, high-tech enterprises related to it have received great attention from stakeholders. Among them, IFLYTEK CO., LTD, (iFLYTEK), whose market value broke through 100 billion, has become the focus of its industry. In this paper, a profit quality pyramid model is constructed from five aspects, including profitability, profitability, structure, sustainability and stability; it comprehensively evaluate its operating status, development opportunities and challenges.
\end{abstract}

\section{Introduction}

In 2017, China's artificial intelligence industry entered a stage of rapid development, and the investment in this field exceeded $¥ 58$ billion. As the "first stock of artificial intelligence", iFLYTEK, while gaining fame, has been constantly questioned in terms of "increasing revenue without increasing profits" and "huge risks".

Therefore, how to evaluate the profit quality of iFLYTEK, whether for internal managers or external stakeholders, is the key problem to be solved. Based on the profit formation process and business operation behavior, and combined with the characteristics of the industry, this paper constructs a profit quality pyramid model, trying to explore the profit quality information of enterprises from multiple angles and provide decision-making basis for multiple perspectives.

In addition, comparative analysis with industry averages (10 companies with similar asset scales) provides a useful reference for the development of internal and external stakeholder management strategies and the realization of management objectives.

\section{Construction of Profit Quality Pyramid Model}

\subsection{Indicator selection}

Founded on December 30, 1999, iFLYTEK was listed on the Shenzhen Stock Exchange in 2008. It is a national software company specializing in intelligent voice and voice technology research, software and chip product development, and voice information services. Since 2017, the share price 
of iFLYTEK has increased by 130\%. The current market value is 80.2 billion, and the price-earnings ratio is as high as 243.25, far higher than the software industry average. However, the net profit attributable to shareholders of listed companies was only 435 million. Thus, for such high-tech enterprises with strong contrasts in the stock market and financial reports, how to evaluate their profit quality has become an urgent problem to be solved.

At present, the academic circles at home and abroad have not yet formed a unified evaluation standard for profit quality.Therefore, in view of the characteristics of iFLYTEK, this paper will construct a profit quality pyramid model consisting of five dimensions of profitability, cashability, structure, sustainability and stability to comprehensively measure the profit quality of iFLYTEK.

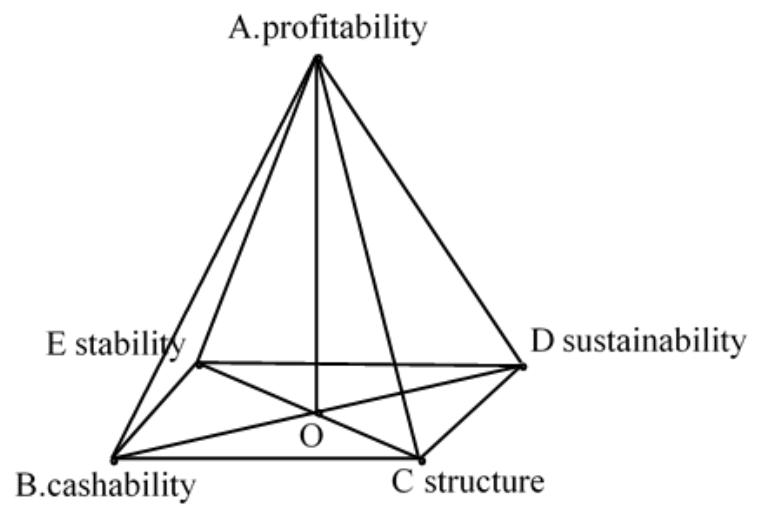

Fig.1 Profit Quality Pyramid Model

As shown in Figure 1, profitablity mainly measures the ability of a company to create profit, which reflects the amount of profit, which is reflected in the model as the vertical height of the pyramid; Cashbility, structure, sustainablity and stability represent the four dimensions of profit quality and form the lateral bottom of the pyramid. It can be seen from the model that the profitability of a company depends not only on the height of the pyramid, but also on the area of the bottom surface. This will ensure the stability of the pyramid, which means the long-term development of the enterprise.

Then, the paper selects two indicators in each dimension: sales gross margin(A1) and ROE(A2) under the profit level dimension measure the ability of enterprise performance appreciation and the degree of return to shareholders; the main business cash ratio(B1) and accounts receivable turnover rate (B2) reflect the bridging of the company's profit and actual cash flow, emphasizing the degree of cash security of profits; the main business profit proportion(C1) and sales\&management expense rate $(\mathrm{C} 2)$ reflect the source and composition of corporate profits, especially the contribution of the main business to profits; EVA growth rate (D1)and R\&D expenditure growth rate(D2) evaluate the growth and growth potential of profit from a long-term perspective; ROA coefficient of variation(E1) and EVA coefficient of variation (E2) reflect the fluctuations in corporate profits and predict the future risks of the company.

\subsection{Data Processing of iFLYTEK and Industry Average}

Due to the different nature of each evaluation index, it is necessary to perform dimensionless processing on the calculation results of the indicators. In this paper, profitability, cashability, structure, sustainability are positive indicators; stability is a negative indicator. According to the calculation method of dimensionless processing, the index value is defined in the range of $[60,100]$.

For positive indicators, $Y=\frac{\mathrm{x}-\mathrm{Xmin}}{\mathrm{Xmax}-\mathrm{Xmin}} \times 40+60$ 
For negative indicators, $Y=\frac{X \max -X}{X \max -X \min } \times 40+60$

Based on the above processing, scores of iFLYTEK and industry average for each indicator in each year are shown in Table 1.

Table 1 Scores of iFLYTEK and Industry Average from 2013 to 2017

\begin{tabular}{|c|c|c|c|c|c|c|c|c|c|c|c|}
\hline \multirow[t]{2}{*}{ Year } & \multirow[t]{2}{*}{ Company } & \multicolumn{2}{|c|}{$\begin{array}{c}\text { A.profitabilit } \\
\mathbf{y}\end{array}$} & \multicolumn{2}{|c|}{ B.cashability } & \multicolumn{2}{|c|}{ C.structure } & \multicolumn{2}{|c|}{ D.sustainability } & \multicolumn{2}{|c|}{ E.stability } \\
\hline & & A1 & A2 & B1 & B2 & C1 & $\mathrm{C} 2$ & D1 & D2 & E1 & E2 \\
\hline \multirow[b]{2}{*}{2013} & iFLYTEK & 81 & 62 & 90 & 63 & 89 & 94 & 77 & 71 & 90 & 95 \\
\hline & $\begin{array}{l}\text { Industry } \\
\text { Average }\end{array}$ & 60 & 61 & 95 & 82 & 90 & 95 & 75 & 71 & 76 & 80 \\
\hline \multirow[b]{2}{*}{2014} & iFLYTEK & 84 & 62 & 92 & 60 & 89 & 94 & 76 & 69 & 87 & 85 \\
\hline & $\begin{array}{l}\text { Industry } \\
\text { Average }\end{array}$ & 68 & 63 & 96 & 89 & 92 & 99 & 77 & 68 & 66 & 71 \\
\hline \multirow[b]{2}{*}{2015} & iFLYTEK & 77 & 61 & 94 & 60 & 88 & 94 & 74 & 70 & 84 & 83 \\
\hline & $\begin{array}{l}\text { Industry } \\
\text { Average }\end{array}$ & 65 & 61 & 97 & 96 & 92 & 98 & 72 & 72 & 73 & 80 \\
\hline \multirow[b]{2}{*}{2016} & iFLYTEK & 79 & 61 & 97 & 61 & 90 & 94 & 73 & 68 & 91 & 86 \\
\hline & $\begin{array}{l}\text { Industry } \\
\text { Average }\end{array}$ & 72 & 62 & 98 & 74 & 95 & 97 & 89 & 75 & 82 & 79 \\
\hline \multirow[b]{2}{*}{2017} & iFLYTEK & 80 & 60 & 95 & 65 & 94 & 94 & 81 & 75 & 93 & 88 \\
\hline & $\begin{array}{l}\text { Industry } \\
\text { Average }\end{array}$ & 71 & 61 & 98 & 71 & 97 & 97 & 74 & 71 & 77 & 80 \\
\hline
\end{tabular}

It can be seen from the table that the profitability, structure and stability of iFLYTEK is higher than the industry average, but the cashability and stability are lower than the industry average.

\section{Cause Analysis}

In the overall comparison, it can be found that the evaluation results of profit quality tend to be inconsistent with the profit level. In order to further explore the specific performance of the five dimensions of the profit quality pyramid model, the following analysis will be carried out one by one.

\subsection{Profitability Indicator selection}

The high-tech industry generally has a high gross profit margin. As the largest provider of intelligent voice technology in China, iFLYTEK has the largest share in the intelligent voice market in China. Due to the high added value and strong competitiveness of the voice products and services provided by the company, the gross profit margin of iFLYTEK is far higher than the industry average, basically at $50 \%$ and above and less volatile within five years.

\subsection{Cashability}

The main business receipt rate reflects the amount of money absorbed by the company's daily business. The greater the amount of money, the higher the cash ratio received by the company to achieve operating income, the less the proportion of accounts receivable. In 2013-2017, the average income of iFLYTEK can earn about 0.9 yuan in cash per yuan, indicating that there are currently receivable projects in the enterprise. And compared with the industry average, the index of iFLYTEK is still low and fluctuating, and needs attention.

Besides, the turnover rate of accounts receivable of iFLYTEK is very pessimistic, not only lower than the average but also declining. This shows that the company has too much capital backlog on the 
receivables, the rate of capital recovery is slow, and the liquidity is getting worse. This may lead to insufficient cash backflow, which may lead to significant financial risks arising from the break of the capital chain.

\subsection{Structure}

The overall evaluation of the scores of the structural dimensions of iFLYTEK is relatively high, but there are still risks. The specific analysis is as follows:The proportion of profit from the main business is to reveal the proportion of the profits of the recurring main business in the composition of corporate profits. In general, companies that want to make significant progress depend on the accumulation of their main business. The higher the ratio, the more stable the company's earnings.In 2013-2015, iFLYTEK 's main business profit share remained above $60 \%$, slightly lower than the industry average, with less fluctuations, and the overall trend showed a steady upward trend.

In 2013-2017, the sales\&management expense rate of iFLYTEK has increased year by year and above the average level, especially the sales expenses and its growth rate. This reflects to some extent the expansion of the sales of iFLYTEK and the rising cost of operation and management. What companies need to pay attention to is that compared with the moderate $R \& D$ investment growth of iFLYTEK, the sales expense ratio has maintained a high growth rate of $60 \%$ in the next two years. This shows that iFLYTEK seems to be tilting the importance of marketing, the business philosophy is very aggressive.

\subsection{Sustainability}

The growth rate of EVA of iFLYTEK is relatively stable.However, in 2013-2016, this indicator has been showing a continuous downward trend and negative growth. Then in 2017, the indicator has risen sharply. It is not difficult to explain because the University of Science and Technology News is in line with the trend of artificial intelligence. The high growth of its EVA has a lot to do with the heat of the concept of artificial intelligence. But, according to the previous trend of the University of Science and Technology, if you only pursue the concept and ignore the benefits that the company really creates, then the University of Science and Technology will face enormous risks.

\subsection{Stability}

The method used to calculate stability in this paper is to use the standard deviation of the data divided by the mean to obtain the coefficient of variation. The coefficient of variation is a negative indicator. The smaller the value, the more stable the business situation in a certain period of time. iFLYTEK performed better in the stability dimension and overall it was better than the industry average.

\section{Conclusions}

Different from the financial performance evaluation of companies that only pay attention to the profit level in the past, the profit quality pyramid model can comprehensively and dynamically analyze the business results, value-added structure, development opportunities and value-added risks, which is beneficial to the company's stakeholder management and company value-added management.

This article takes iFLYTEK as an example to deeply analyze its profit quality: First, on the overall level, the overall score of A's five dimensions is scored to understand the overall picture of the company's profit quality. Then according to these scores, a detailed analysis of each dimension is 
carried out, and it is found that iFLYTEK has insufficient in the following aspects: It relies too much on equity capital, the leverage of debt is not obvious, and shareholders' returns are low;large-scale mergers lead to asset expansion and inefficient use;the performance of accounts receivable recovery is poor, and the cash flow of the main business is weak; Products that rely on core technologies have low gross margins and low profit contribution; Intangible assets are growing slowly, development expenditure is high, and the conversion cycle is long, and R\&D risk is high.

With the increasingly fierce market competition, the internal managers of iFLYTEK must pay attention to the above defects in business management and continuously optimize the level of profit quality management to achieve sustainable development. For external information users, the financial information of profit quality is more conducive to making scientific and rational investment decisions, which is also conducive to stabilizing the order of the capital market and improving the efficiency of resource allocation in the capital market.

\section{References}

[1] Subin Wen, Wensi Li. Management Accounting Tools and Application Cases_A Four-Dimensional Evaluation Model of Enterprise Profit Quality and Its Application. Friends of Accounting,2016(12):129-132.

[2] Aiming Qian, Xinming Zhang. Construction and Test of Three-Dimensional Comprehensive Evaluation System of Enterprise Financial Status Quality_Evidence from China's A-share Manufacturing Listed Companies. Chinese Industrial Economy, 2011(3):88-98.

Reference to a chapter in an edited book:

[3] Ni Wang. Analysis of Factors Affecting the Profit Quality of Listed Companies . Accounting Research, 2012(8):155-156

[4] Subin Wen, Meng Li. Management Accounting Tools and Application Cases_-Application of comprehensive evaluation model of profit quality in cultural media industry. Friends of Accounting, 2016(16):133-136.

[5] Aiming Qian, Xinming Zhang. Reconstruction of Profit Structure Quality Analysis System under the New Standard. Accounting Research, 2008(6):31-38. 